\title{
Vigilante Committees in the Fight against Boko Haram in Cameroon: A Historical and Anthropological Approach of the Integration of Civilians in the Domain of Security
}

\author{
Jean Philippe Ntede Edongo ${ }^{1 *}$, Otye Elom ${ }^{2}$ \\ ${ }^{1}$ University of Douala-Cameroon \\ ${ }^{2}$ University of Maroua
}

*Corresponding Author: Jean Philippe Ntede Edongo, University of Douala-Cameroon

\begin{abstract}
Since terrorist attacks by the Islamic terrorist groups called Boko Haram in Maroua town started, the headquarter of the Far-North Region of Cameroon, vigilance committees were created all over this part of the Cameroonian territory to bring a helping hand to the army in the fight against terrorism. However, they are made up of the local populations recognized by the administration that does not hesitate to provide them with some aid in order to facilitate their task. The presence of vigilance committees also show that when a human community finds itself confronted with a problem, it has the ability to seek for endogenous solutions to solve them, this implies that every project that does not give priority to the community in place is likely to fail. This communication will take place from the internal domain of some populations of the Far-North of Cameroon. This will show how the vigilance committees function as well as their importance to the social life of the populations in this part of the country.
\end{abstract}

Keywords: Boko Haram, terrorism, security, vigilance committee, history, anthropology.

\section{INTRODUCTION}

For some years now, the fight against Boko Haram, especially in the northern part of the country, has led the Cameroonian political authorities to take a set of security measures to better combat this terrorist movement claiming that it is a radical Islamism by specialists of religion. In May 2014, at the end of the mini-summit in Paris, the aim of which was to find effective strategies to fight the terrorist group and ensure security in sub-Saharan Africa, the President of the Republic Paul Biya, invited by his French counterpart François Hollande, declared the "war on Boko Haram", he obviously counted not only on the armed forces of his country, but also on the decisive support of the neighboring countries that are also living this conflict and on the International Community.

This synergetic intervention will prove more or less effective as long as the fight concerns armed groups, but over time, aware of the inequality of power relations, the terrorist group changed destabilization strategy and proceed more and more. Suicide bombings, bringing security experts to talk about asymmetric warfare. Thus out of the conventional framework, the war against Boko Haram will emerge in force a new security group: vigilance committees. The latter, composed of civilians, mostly from the region, have as their main mission to support the armed forces in the fight against Boko Haram. It must be acknowledged that their effectiveness has been proven time and time again, and their actions are echoed more than favorably by the government and the people.

Also, the vigilante committees show that to face a particular problem, each community knows how to find solutions to solve it. It also shows that it is always difficult to act in a human group leaving aside the members of the group. As a result, this redistribution of cards into the security action would be much more effective. We can therefore speak of endo-security to designate the endogenous solutions of a group in the face of a security problem. This article aims to make an ethno-anthropological analysis and interpretation of vigilance committees in the fight against Boko-Haram. If it is true that we find today these in other parts of the country, we will dock our investigations in the Far North where the fight against terrorists is most intense. 


\section{THE METHODOLOGICAL FRAMEWORK OF OUR WORK}

As with any ethno-anthropological and historical endeavor, the method is important for reliable analysis and interpretation. Also, to carry out our research, we put forward the qualitative method with all its rigor as recommended by Jean-Pierre Olivier de Sardan (2001). The intervention of this method allowed us to highlight research techniques such as:

- Documentary research, through which we have been able to identify written documents on vigilance committees and security issues in Cameroon.

- In-depth interviews with some members of the vigilante committees.

- Direct observation. Here we observed how a vigilante committee works, especially in the city of Maroua where we live.

- The story of life. With this data collection technique, we were able to collect testimony from members of vigilance committees.

\section{A PRESENTATION OF THE FAR NORTH CAMEROON REGION}

Before embarking on the historical and ethno-anthropological exercise of the presentation of the vigilance committees in the Far North of Cameroon, it seems to us at first wise to present this region in a synoptic way.

The region under study counts approximately 3.4 million individuals, which makes that it contains $20 \%$ of the total population of Cameroon. It shares borders with Chad and Nigeria, countries that are also undergoing Boko-Haram terrorist attacks. It should be noted that according to several research reports, it is the poorest region of the country, with one of the lowest school attendance rates. We can also see that the health situation here is very worrying. All this, according to many security experts, favors the expansion of the terrorist sect. The region has a Sudano-Sahelian climate, making it one of the regions in Cameroon where the dry season is the longest. There are also several ethnic groups, among which we can mention: Fulbe, Mafa, Massa, Tupuri, Musgum, Kotoko, Arab-Choas, Mussey, etc. Extreme North Cameroon has six departments namely:

The Diamaré Division, whose chief town is Maroua, which is also the regional capital.

- The Logone and Chari Division with Kousseri as its capital.

- The Mayo-Danay Division, withcapital Yagoua.

- The of Mayo-kani Division, whose with capital is Kaélé.

- The Mayo-Sava Division, chief town, Mora

- The Mayo-Tsanaga Divisionwhosewith capital is Mokolo.

All these Divisions are each under the administration of a Senior Divisional Officer (SDO). They also contain districts that are under the administration of Divisional Officers. Note also that the Region is under the authority of a governor. These emissaries of the central administration have to deal with chieftaincies which, according to the case, take the name of sultanate, of lamidat, of lawanat. We can cite the following lamidats: Maroua, Gazawa, Meskine, Kaele, Mokolo, Matakam-South, Guili, Hina, Pouss, Yagoua, Mindif, Mogoda, Bogo, Gawar, Kalfou, Mozogo ... To these lamidates, we can add the sultanates of Mora and Mindif, as well as the cantons of Bangana, Bougoudoum, Gobo, Kar-Hay, Guisey, Wina. Far from having given an exhaustive list of the traditional administrative units here, let us reveal that in view of the current security situation in the region, practically all have one or more vigilance committees. Also, if there were to be an inquiry into the number of vigilance committees throughout the region, it is likely to be close to a hundred.

\section{A bRief EThNOGRaphic aCCOUNT OF Vigilante COMMitTeES IN THE FAR NORTH OF CAMEROON}

During the National Day of Youth on February 11, 2016, members of vigilante committees of the city of Garoua in the Northern Region were invited to parade. Before that, during his end-of-year speech on December 31, 2015, the Head of State had made laudatory remarks for members of the vigilance 
committees, making them models of patriotism. This speech followed the many congratulations received from the Minister of Communication and the Governor of the Far North Region. In December 2015, the Head of State did not hesitate to award medals of honor, including Chevalier du MériteCamerounais to four members of vigilante committees, three posthumously for their bravery in the face of attacks by the terrorist group. As a prelude to the preparations for the Unity Day on May 20, 2016, a banner honored the vigilante committees with the following inscription in English: " vigilante Committees: a vital force in the fight against Boko Haram".

These examples show that the main actors of these organizations are very important in the fight against the terrorist group. It also shows that it is the young people who constitute the spinal cord of the vigilante committees in that they still have a physical vigor that allows them to comfortably perform the various security tasks assigned to them. Finally, we can note that the vigilante committees now occupy a place of honor in Cameroon's security system. Never mind, it is advisable, before dwelling on the vigilante committees in the Region of the Far North, we will present the history of these latter.

\subsection{A Brief History of Vigilance Committees}

It is important to note that the reality of vigilance committees did not appear in Cameroon with the presence of Boko Haram on the national territory. Indeed, several historical events related to security failures or the need for the state to optimize its internal security have often justified their formation. Without necessarily claiming a certain exhaustiveness, let us emphasize that it in the 1960s just after the country's independence that the embryonic elements of the vigilance committees will emerge. It was already during this period to help the Cameroonian army to fight the nationalist rebellion of the Union of Cameroonian Populations (UPC), a communist-inspired political party that had already fought for autonomy during the war. French occupation in the 1950s and who believed that the new leaders installed after independence protected neither more nor less the interests of the former colonist. It was therefore for the administrative authorities to ensure the support of the people by involving them directly in its security process.

During this period, the term terrorist was already used to describe rebels. However, according to Prosper Nkou Mvondo, it is the 1980s that mark the real appearance of vigilante committees. He confides on this theme that:

"It was in 1984 that we heard about vigilance committees for the first time in Cameroon. At the time, they were groups organized in the neighborhoods and villages with the blessing of the power in place to denounce to the public authorities the political troublemakers and all those who, by any means whatsoever, would seek to put endanger peace in Cameroon. The vigilante committees had then only a purely political role. "(Nkou Mvondo, 2002: 379).

The vigilante committees will sharply resurface in the 1990s, marked by an unprecedented economic crisis that caused political violence called ghost towns, and occurred "when new political groups emerged and gathered enough support to be heard and provoke. Important institutional changes. (Marie-Emmanuelle Pommerolle, 2008: 75). Once again, vigilante committees will need to provide necessary support to the security forces, especially in the face of looters who took advantage of political violence.

By limiting ourselves to these two historical events, we can say that the fight against the terrorist group Boko Haram constitutes the third major appearance of vigilance committees in the history of Cameroon. What must be remembered, however, is that today, they are virtually unanimous among the population, because it is a question of fighting a common enemy. And even opposition parties that are often virulent against the state accept their presence. The only criticism of the power in power is that it does not provide enough resources to these committees. Today, in addition to the Far-North, where they prove to be more than indispensable, the vigilante committees are present in several other cities. The aim is not only to prevent the terrorist threat that can be shunted to other parts of the country, but also, to a anextent, to protect citizens more effectively on a daily basis. Beyond their ability to intervene with knives, their role in gathering information is far from negligible. It must be acknowledged that since their creation, they have been so successful that the President of the Republic does not hesitate to reward some of their members. There are even vigilante committees in several 
other cities where the threat is less increased as Yaounde the Capital or Douala. All of this shows that to maintain security in a territory, the military imperatively needs civilians for more effective results.

\subsection{Organization of a Vigilante Committee in the Far North of Cameroon}

Even if in many other Cameroonian cities today we note the presence of vigilante committees, those of the Far North deserve special attention because they are at the heart of the battle against the terrorist group Boko Haram. In this part of our presentation, it will be a question of giving an ethnographyof the vigilante committees in a synoptic way, referring to their organization and functioning.

As we have seen above, vigilante committees are generally created in each neighborhood and village. Generally, in the Extreme-North Region of Cameroon, a vigilance committee has a supervisor or president who is usually the chief of a district or village called djaoro. It is the latter who, following a crisis meeting, chooses the individuals who will be part of the vigilance committee. Note that to be part of a vigilante committee, you have to submit to a kind of morality investigation. After having done this work, the Divisional Officer submits the list of the members to the Lamido, a kind of superior chief that one can relate to a sovereign and imposing his authority on a more or less wide territory. The lamido will then endorse the list by the Divisional Officer of the area to give a much more administrative character to the security action that is implemeanted. While investigating with the services of the Governor of the Far North, we obtained two circular notes concerning the creation of a vigilante committee: one dated June 5, 1997 establishing a vigilanee committee in the neighborhood DougaiSarkiyayi in the town of Maroua and the other dating from 30 September 1998 and creating a vigilante committee in the Marouare district in the city of Maroua. According to these circulars signed by the Divisional Officer of Diamaré, here are the missions of the vigilante committee that remain in force until today according to the testimony of one of the officials interviewed:

Organize day and night surveillance groups according to the sectors of the district (or village) under the supervision of the Commissioner of Public Security of Maroua (Urban Center) or the Commander of the Territorial Brigade of Gendarmerie of Maroua (Rural Area). Dams and other barricades are prohibited.

- To denounce to the Administrative Authorities and the maintenance of the Order, all the acts or the individuals likely to disturb the good order.

- To inform the administrative, municipal and traditional Authorities, and to supplement the forces of maintenance of the Order in their tasks of surveillance of the territory.

- To apprehend without violence the individuals considered dangerous or caught in the act of any wrongdoing and to take them to the authorities for the continuation of the procedure.

The circular concludes by making it clear that under no circumstances should the committee take the place of the Administrative Authorities or substitute itself for the Tribunal. If necessary, the administrative authority or the municipal authority may entrust the committee with a mission within the framework of the administrative police, with a view that a detailed written report of the actions taken must be taken in twenty-four hours to the Divisional Officer by the Chairman of the Committee.

Our field investigations indicate that the members of the VigilanTe Committee are mostly young people, whose age generally varies between fifteen (15) and forty (40) years. These are obviously people with good morals and willing to sacrifice themselves to defend their area of origin. The vigilance committees are divided into small groups of at least three members, headed by leaders. Generally, these group leaders are often close relatives of the neighborhood or village chief; which is not without producing some discontent, especially that it is important to specify that the economic aspect made a not insignificant entry, we will return to it below. In the Meskine lamidat, a peripheral neighborhood located about five kilometers from downtown Maroua, we took information on two blocks: in the block of Tchasdeo, twelve members of the vigilante committee are responsible for ensuring security; while in the Dougoïwo block, there are seven (07). The Vigilance Committee here usually conducts night patrols that range from twenty hours to four hours. During the day, the surveillance is especially increased on Wednesdays, which is a market day, therefore a day of great affluence of individuals. To return to the economic aspect note that the vigilance committees live 
mainly donations from the administrative authorities, including those of the President of the Republic who still know an informational media report.

The equipment of members of vigilance committees is usually composed of sticks, machetes, bow and arrow, knives. In some vigilance committees in the Region, traditional firearms are tolerated. It should be noted that these weapons mainly have the role of dissuading possible criminals, it is to scare them while waiting for the intervention of the official security forces. In this equipment, we also find longrange flashlights that not only allow to have a better view, but also to maintain a distance communication between members of the committee and passers-by. The members of the vigilante committee are also identifiable by badges.

\subsection{The Activities of Vigilance Committees in the Far North of Cameroon in the Fight against Boko Haram}

The honors given to the members of the vigilante committees not only by the administrative authorities, but also and above all almost unanimously by the people are undoubtedly the result of their effective activities against Boko Haram terrorism. Indeed, since they were granted some freedom of movement, they have managed to control several attacks, and this, often at the risk of their lives, because note, since the beginning of the conflict, several members from these committees were found death. It should also be revealed that their actions are especially significant in the prevention of attacks-suicide bombers. With the advantage of knowing the inhabitants of the district or the village better, it is easier for the members of the committees of vigilante to identify the foreign persons, who practically act like suspects. It is also easier for them to detect the unusual behavior of a member of the country and thus pinch him if he is in collusion with the terrorists. Also, it rarely happens a week without anyone being aware that members of a vigilante committee have managed to prevent a kamikaze from making victims. And to the extent that there are, the losses are not as heavy as they would have been without their intervention. We can therefore admit without circumlocution that in the fight against attacks-suicide bombers, the action of vigilante committees is significantly more effective than that of the armed forces involved. The latter are also relieved to the extent that it allows them to better focus in the conventional war against Boko-Haram. We will not attempt here to make an inventory of the brilliant actions of the vigilante committees in the fight against Islamist terrorism of Boko Haram. It is simply a matter of showing how, in an armed struggle, civilians have the opportunity to participate actively, and even sometimes to rob the star of the army.

\subsection{The Difficulties Encountered by the Vigilance Committees}

Aware of the important strength they represent in Cameroon's fight against Boko Haram, the vigilante committees rightly claim that their working conditions are improved. Indeed, among the difficulties identified with their members is the lack of equipment to carry out their missions. Indeed, according to an informant of the vigilante committee of Meskine, all the members of the vigilante committee do not have yet an adequate dress. There are also complaints about financial support to enable members of vigilance committees to better ensure the safety of people by constantly updating their work equipment. Some members of the vigilante committee of Meskine regret that the Maroua I Council in charge of looking after them, shines by a lack of involvement. The members of the Wolangare vigilance committee more than one hundred kilometers from the city of Maroua, they complain much less, because they have equipment that is not far from resembling that of soldiers and can boast of benefiting a number of doles, such as donations of foodstuffs or the granting of motorcycles by the State. They are also fortunate to have a retired military advisor.

\section{The Vigilante COMmitTeES In THE FAR NORTH OF CAMEROON AND THE ENDO-CULTURE}

By endo-culture here we mean the cultural reality as apprehended by the members who live it in daily basis. Indeed, if we recognize that by proceeding by an etic approach or look of members outside the community, vigilante committees are more than appreciated. It is thus necessary to recognize that the people who experience their daily existence are the most appropriate to have a real vision or the full meaning of these anti-terrorist organizations. In other words, it is the emic approach that will better help us to have the cultural representations on vigilante committees in the fight against Boko Haram in the Far North of Cameroon. 
Also, we can report from our observations, that vigilante committees are also very appreciated in the sociocultures where they are present. They provide people with a clear sense of security. Indeed, members of vigilante committees are individuals who are certain that they will almost never leave the land, while the armed forces are likely to leave one day or another. Their knowledge of the field also accentuates this feeling of security; which leads the populations to collaborate easily with the administrative authorities, in so far as they are no longer objects in the maintenance of their security, but also, and not only a little, subjects. Added to this sense of security is a sense of pride. The latter stems from the fact that members of the vigilante committees are as honored as the armed forces, since they also receive praise from all sides of the national triangle. Despite all the more significant work done, they do not have such sophisticated equipment as the army. This is not really an exaggeration when some consider that vigilante committees are somehow at the forefront of the fight against Boko Haram. vigilante committees are also an opportunity for some young people to come out of idleness that could have led them to become delinquents.

However, one can note depreciative affirmations on the vigilante committees. Also, some people think that the members of these committees do not hesitate sometimes to use their status to commit abuses. According to many testimonies that we have been able to collect, some members of these committees do not hesitate from time to time to ransom passers-by, even if it turns out that they are in order. The other criticism of the populations is that the recruitment of the members of these organizations is not always serious. And what explains this is that for some time, being a member of a vigilante committee confers a certain number of advantages, like taking advantage of the donations of the administration which are summed up most often with foodstuffs, motorcycles, money. There is therefore the problem of recruitment made on the basis of nepotism, which means that some chiefs in charge of recruitment are accused of shenanigans by privileging either the members of their families, or those who pay them a prior due. It is not uncommon to see individuals with questionable mentality in the ranks. The information we received from the vigilante committee of the Douallare district in the city of Maroua reveals to us that some young people who were part of it were involved in burglaries and robberies in the neighborhood. It has even been revealed to us that some members of this committee were convicts. In the vigilance committee of Wolangare village, it is the sometimes gratuitous brutality of its members that is often questioned. In Meskine, we note the complaints of mototaxis who believe that the vigilance committee does not allow them to work calmly, because it proceeds according to them to an exaggeration of controls and does not allow them to work after eight $\mathrm{pm}$, which reduces considerably their daily income. It is these abuses that have been recognized for many years by these self-defense groups that led Ngwa Fobin to question "... the legal situation of vigilante committees, which are otherwise prohibited by the general principles of law. (Ngwa Fobin, 2004: 19) Despite this, everyone agrees that vigilante committees have their place in maintaining security. If there are sometimes criticisms within populations, it is because we often notice slippage.

\subsection{An Ethno-Anthropological Analysis and Interpretation of Vigilance Committees in the Far North of Cameroon}

Scientific rigor always requires a thorough analysis and interpretation of the phenomenon of interest. In anthropology, to feel at ease in this exercise, it is most often appropriate to rely on a theoretical framework. In this case, the notion of cultural role that can be taken from the functionalism of Bronislaw Malinowski (1968) and those of ethno method and endosemia that we borrow respectively from the ethnomethodology of Harold Garfinkel (1987) and the ethno-perspective of MbonjiEdjenguèlè (2005) will serve as a cornerstone for the comprehensibility of our data. The first point on which we will focus is to show that endo-security in the Far North of Cameroon is a phenomenon that has long been a part of the cultural ethos of the communities of this region.

\subsection{Vigilance Committees: An Endo-Cultural Reality in the Far North Cameroon}

Security problems have always been topical in the Far North Region of Cameroon. Also, one can easily understand that the massive adherence of these ones and the other vigilantecommittees corresponds to a logic of conflict which the populations of this region have always experienced. Where some might be surprised to see individuals willing to risk their lives with more or less rudimentary equipment, the most discerning see the current phenomenon Boko Haram, an opportunity for members of different ethnic groups in this region showing that they are able to defend their 
families. Indeed, according to our investigations, we can realize that this region has often been the subject of many conflict situations. Border populations have been facing attacks by the Buduma ethnic group for decades in Nigeria and Chad. These attacks are mainly aimed at stealing cattle. In addition, as shown by Deli TizeTéri (2005), it can be noted that interethnic conflicts for the occupation of spaces are legion in the area. The author mentioned was more focused on the violent and regular conflicts between Kotoko, Arab-Choas, Bornu and Musgum for the occupation of fishing areas. It is also rare that these conflicts are responsible for many murders, regularly requiring the security forces to intervene. In addition, the region has been crowded with hostage takers and looters, leading people to organize themselves for their safety. All this to say that the fight against Boko Haram is just another conflict.

Also, according to some of our informants, the vigilance committees can easily be related to the selfdefense groups that have existed since the pre-colonial period, named doka in fufulde, the language most commonly spoken in the region. These groups consisted of "soldiers" from different families in a locality. Their role was to patrol at night, usually armed with batons and to warn in case of danger. It becomes easy to understand why in the fight against the terrorist group today, vigilante committees are so effective as to often supplant the regular army. We also understand why they are so courageous, this is because they are used to fighting. According to an informant, here, if an individual does not fight and if need be, until death, to defend what is his, he is not a man. It is therefore this capacity for resilience that enables the populations in this region to easily integrate, despite the proven risks, the vigilante committees.

\subsection{Vigilante Committees as a Holistic Cultural Phenomenon in the Far North Cameroon}

By holistic cultural phenomenon, we mean, like the total social fact of Marcel Mauss, a fact belvedere culture, to highlight other facts of culture. The observation of the vigilance committees under the prism of the analytical and interpretative schemas of anthropology makes it possible to highlight several sections of the cultural fabric of the different communities of the Far North of Cameroon.

At the level of kinship, adherence to vigilante committees strengthens bonds and sense of belonging to the same community. Recruitment is also taxed as we have shown above, to highlight a nepotistic system where, most often, it is the relatives of recruiters who are usually part of these security groups. We are therefore witnessing the sacredness of kinship bonds, and no traitor can be admitted. This is why we are ready to arrest anyone suspected of helping the Islamist sect. This would mean that such a person only thinks of his or her personal interests, which is unacceptable. In the vigilante committee of Wolangare, we have been told cases of individuals who had to flee the locality because they were suspected of colluding with Boko Haram. These suspicions arose from the fact that their family members realized that they had suddenly become wealthy, without knowing the source of their income.

At the religious level, we can say that the fight against the terrorist group by integrating vigilante committees is also somehow a way to defend Islam considered by a good fringe of public opinion, as a religion of violence. Seen in this sense, Boko Haram thus conveys an evil Islam, an Islam that has nothing to do with the one that the practitioners of this religion want to promote. The massive adherence to the vigilante committees thus reveals a struggle to restore its place to a true Islam that does not refuse to cohabit with other religions.

As for the safeguarding of cultural identity, one can also understand adherence to vigilance committees, especially for an ethnic group especially: the Kanuri. Indeed, it is necessary to know that the leader of the terrorist sect Boko Haram, Abubakar Shekau, is a Kanuri. This means that there is currently a kind of stigmatization against members of this ethnic group. Also, the Kanuri are the most active in vigilance committees, even if this is not enough to prevent the suspicion of other communities that suspect them of helping their "brother". We understand their commitment to help the government because they feel they have been dishonored. In addition to the Kanuri, the other ethnic groups of the Far North Cameroon believe that in other parts of the country, they are also seen as potential accomplices of Boko Haram, because this situation would allow them to conquer the supreme political power. It is then for them to show that they are the fiercest opponents of this group. Let us reveal that a good part of public opinion, as well as some media relayed for a long time that the phenomenon Boko Haram was neither more nor less than a rebellion orchestrated by some barons of 
the regime from of the Far North, to seize power by a coup d'etat. It must be recognized that since the involvement of civilians in the struggle, these claims are virtually non-existent.

By observing the vigilante committees on the artistic side, we see that clothing is important, to the point that those who cannot complain about it. The garment here makes it possible to distinguish oneself from other members of the locality and thus accentuates the feeling of pride. By wearing a particular outfit, members of vigilante committees also think that they are taken much more seriously.

At the economic level, one can obviously realize that the vigilante committees are a space to obtain gifts that come from the State and the populations. These donations can range from financial resources to food and motorbikes. In addition, these vigilante committees allow people to be able to go about their daily activities. In a context now marked by food insecurity, it is essential that people resume farming activities.

At the medical level, vigilante committees provide psychological support to populations that cannot be neglected. These populations must be remembered, live the trauma caused by the attacks and in the psychosis of other potential attacks. Indeed, we know that in the African context the disease goes well beyond the organic body and integrates

\subsection{Vigilante Committees in the Far North of Cameroon and Two Principles of African Epistemology}

African epistemology allows for a specific vision of cultural realities in Negro cultures. Developed by MbonjiEdjenguèlè (2001), the principles of African epistemology reveal that it is not possible to have a deep understanding of African cultures in the light of Western societies. Two of these principles are of interest to us in our interpretation of vigilante committees: the principle of multi-symbolism and the principle of the relative absolute.

The principle of multi-symbolism puts forward the idea that in a "... same cultural context, a symbol can have several meanings, have several assignments of meaning. (MbonjiEdjenguèlè, 2001: 111). By applying it to the reality of vigilante committees in our study site, we can affirm the presence of uniforms or badges symbolizes the maintenance of security. These elements are also symbols of attachment to one's community of belonging. For many, wearing a uniform or badge denoting its adherence to a vigilante committee is also a symbol of courage, when we know the risks that entails.

When it comes to the principle of the relative absolute, it "... refuses the totalitarianism of the unique, of the one; the absoluteness, the aseety of any being. (MbonjiEdjenguèlè, 2001: 126). By putting vigilante committees in the light of this principle, we can observe that they allow a relay of hegemony among security actors against the terrorist group Boko Haram. Indeed, the armed forces are not always the most powerful to fight effectively this enemy. They now need these civilians for more effective synergistic security action. It subsumes that sometimes it is the legal armed forces that are put forward and sometimes, it is the vigilante committees that steal the show. In short, each of the two forces knows its moments of glory with public opinion, so it is not only the army that reap laurels, as it was at the very beginning of the conflict.

\section{CONClusion}

At the end of our research on the involvement of the vigilante committees in the fight against the terrorist group Boko Haram in the Far North of Cameroon, we can say that these groups of civilians play an important role that can give them a significant place of the fight that Cameroon has been taking place for a few years. We realize that the political authorities now give them a place of choice and are aware that they are undoubtedly key players in the success of this fight. In short, it can be said that, had the vigilance committees previously received a mixed reception because those who were under their influence were first and foremost other Cameroonian citizens who seek only to express themselves freely today. Now, despite differences that can be noted here and there, we can agree on the fact that they are acclaimed in the fight against Boko Haram. All this shows that security issues are not only a matter for the armed forces of a country, but that in a conflict, good cooperation between civilians and the military is always more effective. The present article thus stands at the edge of the anthropology of security and war, showing how human groups find endogenous responses to defend themselves from external attacks and know how to adapt to conventional or asymmetric 
warfare as a function of context. This reflection can also be situated in the anthropology of honor, because it is seen that in order to prove their courage and defend their interests, members of a group can agree to sacrifice their lives for a cause they consider just.

\section{REFERENCES}

[1] Belomo Essono, P.C., 2009, «Sécurité et ordre politique au Cameroun : entre dynamiques internes et connexions internationales », in Revue Africaine des Relations Internationales, Vol 12- Nos 1\&2, pp.3980, Codesria.

[2] Deli TizeTéri, 2005, Les Conflits des pêcheries à Logone-Birni dans l'Extrême-Nord du Cameroun, Mémoire de Maîtrise en anthropologie, Université de Yaoundé I.

[3] Garfinkel, H., 1987, Studies in ethnomethodology, New Jersey, Prentice Hall.

[4] Malinowski, B., 1968, Une Théorie scientifique de la culture, Paris, Maspéro.

[5] MbonjiEdjenguèlè, 2001, La Science des sciences humaines. L'anthropologie au péril des cultures? Yaoundé, Editions Etoile \& MIC.

[6] MbonjiEdjenguèlè, 2005, L'Ethno-perspective ou la méthode du discours de l'ethno-anthropologie culturelle, Yaoundé, Presses Universitaires de Yaoundé.

[7] Ngwa Nfobin, EH., 2004, «Les Comités de vigilance et l'Etat de droit au Cameroun », in Cahiers Africains d'Administration Publique, $\mathrm{N}^{\circ}$ 62, pp. 19-32, Centre Africain de Formation et de Recherches Administratives pour le Développement.

[8] Nkou Mvondo, P., 2002, «La Justice parallèle au Cameroun : la réponse des populations camerounaises à la crise de la justice de l'Etat», in Revue Droit et société, $\mathrm{N}^{\circ}$ 51-52, pp. 369-381, Editions Juridiques Associées.

[9] Pommerolle, M.E., 2008, «La Démobilisation collective au Cameroun : entre régime postautoritaire et militantisme extraverti », in Revue Critique Internationale, $N^{\circ}$ 40, P.P. 73-94, Presses Universitaires de Sciences Po.

[10] Sardan (de), J-P.O, 2001, La Rigueur du qualitatif. Les contraintes empiriques de l'interprétation socioanthropologique, Louvain-la-Neuve, Academia-Bruylant.

Citation: Jean Philippe Ntede Edongo, Otye Elom. “Vigilante Committees in the Fight against Boko Haram in Cameroon: A Historical and Anthropological Approach of the Integration of Civilians in the Domain of Security". International Journal of Humanities Social Sciences and Education (IJHSSE), vol. 6, no.6, 2019, pp. 49-57. doi: http://dx.doi.org/ 10.20431/2349-0381.0606007.

Copyright: () 2019 Authors. This is an open-access article distributed under the terms of the Creative Commons Attribution License, which permits unrestricted use, distribution, and reproduction in any medium, provided the original author and source are credited. 